\title{
Correction to: Effect of vibration characteristics and vibror arrangement on the tactile perception of the upper arm in healthy subjects and upper limb amputees
}

Matthieu Guemann ${ }^{1 *}$, Sandra Bouvier ${ }^{2}$, Christophe Halgand ${ }^{1}$, Florent Paclet ${ }^{1}$, Leo Borrini ${ }^{3}$, Damien Ricard ${ }^{4}$, Eric Lapeyre ${ }^{3}$, Daniel Cattaert ${ }^{1}$ and Aymar de Rugy ${ }^{1,5}$

\section{Correction to: J Neuroeng Rehabil}

$$
\text { https://doi.org/10.1186/s12984-019-0597-6 }
$$

The original article [1] contained an error whereby the captions to Fig. 3 and Fig. 8 were mistakenly interchanged. This has now been corrected.

Furthermore, this error was mistakenly carried forward by the production department which handled this article, and thus was not the fault of the authors.

\footnotetext{
Author details

'Team HYBRID; INCIA laboratory, CNRS UMR 5287, University of Bordeaux, 146 rue Leo Saignat, 33076 Bordeaux, France. ${ }^{2}$ University Descartes, Paris, France. ${ }^{3}$ Departement of Rehabilitation at the Army instruction Hospital, 1 Rue du Lieutenant Raoul Batany, 92190 Clamart, France. ${ }^{4}$ Department of Neurology at the Army instruction Hospital, 1 Rue du Lieutenant Raoul Batany, 92190 Clamart, France. ${ }^{5}$ Centre for sensorimotor performance HMNS, University of Queensland, Brisbane, Australia.
}

Published online: 19 February 2020

\section{Reference}

1. Guemann $M$, et al. Effect of vibration characteristics and vibror arrangement on the tactile perception of the upper arm in healthy subjects and upper limb amputees. J Neuroeng Rehabil. 2019;16:138 https://doi.org/10.1186/ s12984-019-0597-6.

Full list of author information is available at the end of the article 


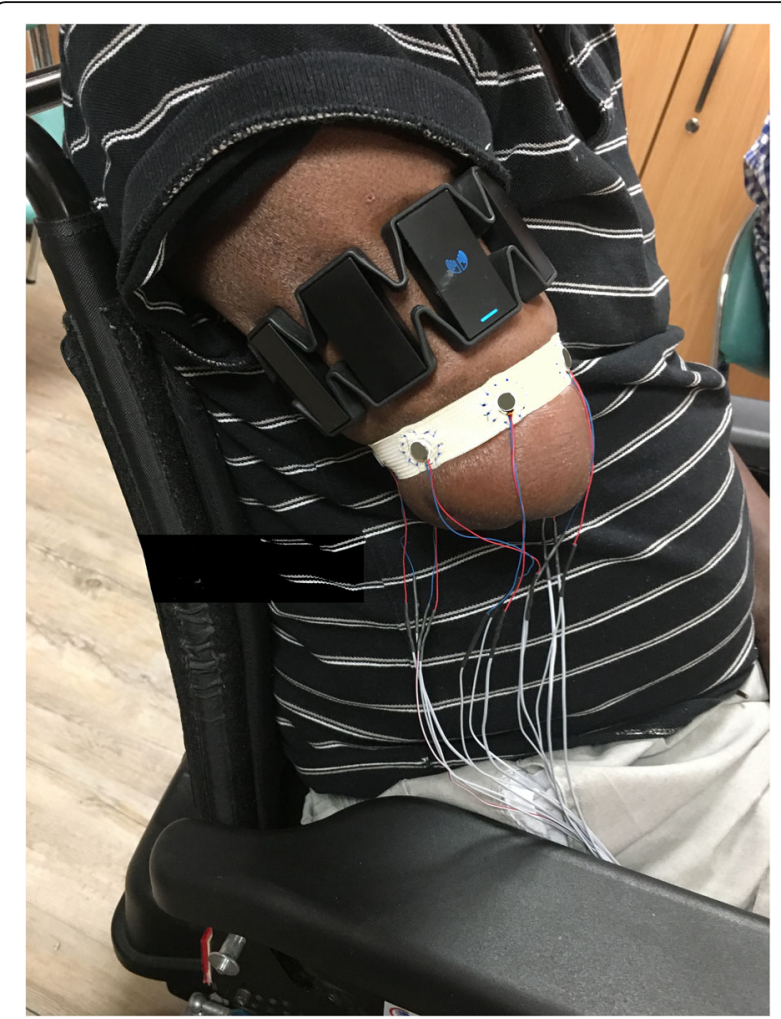

Fig. 3 Example of one patient with vibrors encapsulated in a plastic piece and attached to an elastic band by surgical file

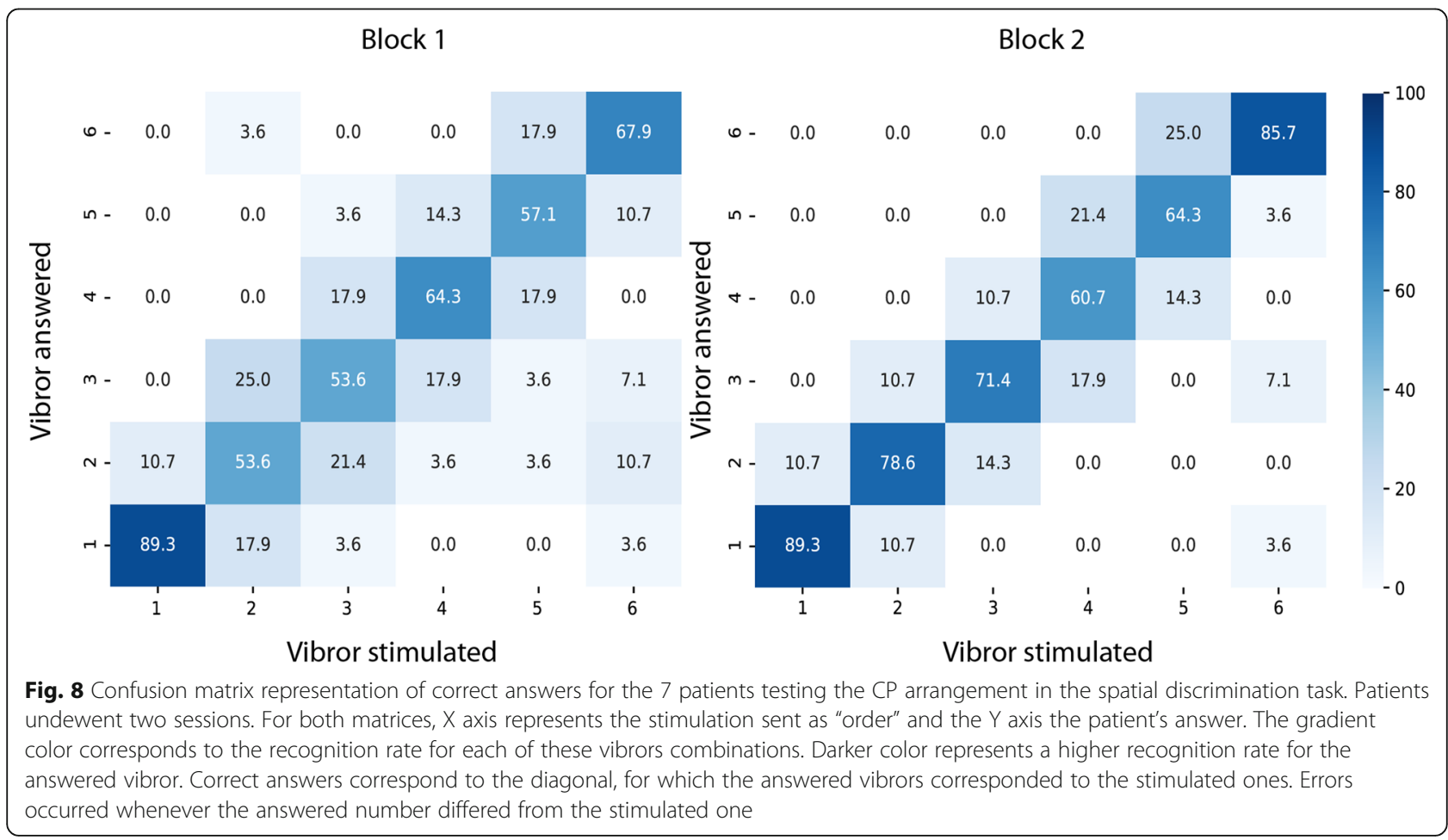

